\title{
Past, Present and Future Trends of Non-Radiative Wireless Power Transfer
}

\author{
S.Y. Ron Hui
}

\begin{abstract}
Although non-radiative wireless power transfer (WPT) was invented over a century ago, it has regained research and development interests in 1980s. Over the last 15 years, WPT has appeared as an "emerging" technology that has attracted wide-spread attention in both academia and industry. Because of the long history of WPT research and developments, researchers of the modern days often do not know some historical milestones of WPT. This paper aims at providing a brief history of some key concepts and technologies that pave the way for modern WPT research and applications. A few misconceptions of WPT technologies are particularly highlighted so that new researchers entering this research field can avoid such pitfalls. Finally, some discussions on present and future trends of WPT are included.
\end{abstract}

Index Terms-Wireless power transfer, magnetic resonance, inductive power.

\section{INTRODUCTION}

$\mathrm{T}$ HE scientific breakthroughs of the French Scientist André-Marie Ampère (1775 -1836) and English scientist Michael Faraday (1791-1867) in early $19^{\text {th }}$ century laid down the foundation of electricity and electromagnetism. The Ampere's law, Faraday's law and electromagnetism form the pillars of modern electrical engineering. Their work was further enhanced by Scottish scientist J.C. Maxwell who developed the well-known Maxwell's equations for electromagnetic fields and waves. These scientific principles became the tools for early WPT pioneers, such as Tesla, Hutin and Leblanc [1]-[3], to explore WPT through the use of coupled alternating magnetic field.

Among early WPT pioneers, Nicola Tesla was undoubtedly the most influential scientist/engineer in WPT research. Tesla was recognized as a highly visionary inventor who was well ahead of his time [4], [5]. His many inventions such as a.c. machines, ac power generation and transmission, radio transmitters and receivers, X-ray machines and the world's first remote-controlled technology have been used for over a century. Although some of his inventions have been improved over time with the availability of more advanced technologies, their basic concepts are still being used every day in modern societies.

This work was supported by the Hong Kong Research Grant Council under the project: 17255916 .

The Author is with Department of Electrical \& Electronic Engineering, University of Hong Kong and Imperial College London. (e-mail: ronhui@ eee.hku.hk)

Digital Object Identifier 10.24295/CPSSTPEA.2016.00008
Between the WPT research of Tesla in late $19^{\text {th }}$ century to mid 1980s, while research in WPT was still active in medical implants, commercial applications of WPT was not wide spread. Tesla pointed out that WPT could take place through magnetic coupling at high frequency and under resonance conditions. To maintain high energy efficiency, WPT requires (i) windings with low resistance at high frequency operation and (ii) a high-frequency power source. While Litz wires have become available since 1950s, high-frequency switching power electronics switches (namely power mosfets) only became commercially available in 1980's. The availability of high-frequency power sources based on power electronics technology certainly makes it easy to realize economically the high-frequency power source in a compact form. Such historical developments of Litz wires and power electronics explain why research in magnetic resonance based WPT took off for medical implants [6], [7] in late 1980s and electric vehicles and inductive power pickups in mid 1990s [8], [9]. The dawn of the mobile phone era in mid 1990s also prompted active research in wireless charging for portable electronics [10][15]. Reviews of near-field WPT for a range of applications starting from low-power consumer electronics [16] to relatively high-power inductive power pickup systems in manufacturing industry [17] have been reported.

The publicity of an article by the M.I.T physics team in Science [18] about the use of a 4-coil WPT system to power a light bulb over a distance of $2 \mathrm{~m}$ in 1997 is an important factor that raises intensive interest in WPT in late 1990s. For high energy efficiency WPT, the authors of [18] claimed the use of magnetic resonance and identified a "strong coupling" regime as:

$$
\kappa / \sqrt{\Gamma_{1} \Gamma_{2}}>>1
$$

where the symbol $\kappa$ is related to the mutual coupling coefficient $k$ as $\kappa=\left(\frac{\omega}{2}\right) k ; \Gamma_{1}=\frac{\omega}{2 Q_{1}}$ and $\Gamma_{2}=\frac{\omega}{2 Q_{2}}$ are the intrinsic loss rates of the first resonator and the second resonator respectively. Here, $k$ is the mutual coupling coefficient, $\omega$ is the angular frequency, $Q_{1}$ and $Q_{2}$ are the quality factors of the two magnetically coupled windings. According to [18], the condition of (1) is "a regime of operation that has not been studied extensively". Equation (1) can be expressed in standard electrical engineering terms as:

$$
\frac{\kappa}{\sqrt{\Gamma_{1} \Gamma_{2}}}=\frac{\left(\frac{\omega k}{2}\right)}{\left(\frac{\omega}{2 Q_{1}}\right)\left(\frac{\omega}{2 Q_{2}}\right)}=k \sqrt{Q_{1} Q_{2}}
$$


It can be seen that the term $\kappa / \sqrt{\Gamma_{1} \Gamma_{2}}$ of the coupled mode theory is equal to $k \sqrt{Q_{1} Q_{2}}$ in electric circuit theory. Thus, $\kappa / \sqrt{\Gamma_{1} \Gamma_{2}} \gg 1$ simply means $k \sqrt{Q_{1} Q_{2}} \gg 1$. The idea of ach ieving high energy efficiency in WPT through the maximization of the product of the mutual coupling and quality factor (i.e. $k Q$ ) has been a well-known concept for many decades. Several research teams have independently studied the WPT equations based on the coupled mode theory and transformed them in standard electric circuit theory [19]-[21]. Their analyses are consistent that the work in [18] can well be explained in standard circuit theory. The idea of achieving high energy efficiency in WPT through the maximization of the $k Q$ product has been a central principle among power electronics researchers for decades. For short-range applications in which magnetic coupling is relatively large (i.e. with a large $k$ ), winding with reasonably high $Q$-factor will lead to high efficiency. For mid-range applications in which $k$ is a small value, a very high $Q$-factor is needed in the magnetically coupled windings.

The fact that such a well-established electrical engineering concept has become a factor to spark off new research interests in WPT is intriguing. One obvious reason is the lack of relevant WPT background among researchers who recently joined this research field. It is the objective of this paper to highlight some historical facts and R\&D activities relevant to high-efficiency WPT concept expressed in (2) and explain such well-established idea has been used for decades and is still being used in modern WPT applications [22]. Remarks on the current status and future trends of WPT are also included in this paper.

\section{The PAST}

\section{A. Magnetic Resonance was well established in Tesla's works}

Since the end of the $19^{\text {th }}$ century, "resonance" was a common theme in several aspects of Tesla's such as radio and TV transmitter and receiver circuits. The use of inductivecapacitive (LC) resonant circuits was the basic concept adopted in many of Tesla's high-frequency works. In his 1893 lecture delivered to the Franklin Institute, Philadelphia [23], he experimented with "condenser in series with the self-induction". (Note: condenser is equivalent to capacitor in modern electrical engineering term.). This inductivecapacitive (LC) resonant circuit was fed by a high-frequency alternator. To achieve resonant operation, he remarked that "both capacity and self-inductance were adjusted to suit the dynamo frequency". This means that the inductance and capacitance values of the LC circuit were tuned to suit the frequency of the voltage excitation.

In Tesla's time, high-frequency power generator was not commercially available because high-speed power semiconductor switches had not been invented yet. Historical records show that Tesla developed his high-frequency power source based on generators with a high number of pole pairs. In the article of his high-frequency tests [23], the frequency was set in the range of $5 \mathrm{kHz}$ to $10 \mathrm{kHz}$. Among various WPT circuits tested by Tesla, two examples are shown in Fig. 1(a) and Fig. 1(b). In Fig. 1(a), a condenser (i.e. a capacitor) is connected across the primary coil $(\mathrm{P})$ to form a parallel resonant circuit, which wirelessly transmit power to the secondary coil (S). The two output terminals of $\mathrm{S}$ are labelled at $\mathrm{T}$.

In Fig. 1(b), the high-frequency voltage generator is fed to a transformer, the outputs of which are connected to the transmitter circuit of the system. The transmitter circuit comprises two parallel condensers are connected in series with the primary coil $(\mathrm{P})$. This arrangement forms a primary series resonant tank. In the receiver circuit, each end of the secondary winding ( $\mathrm{S}^{\prime}$ ) is connected to two parallel plates (labelled as $t$ and $t^{\prime}$ ) that form a variable capacitor. This arrangement forms a secondary series resonant circuit. In modern terminology, this system setup is equivalent to a magnetically coupled seriesseries resonant WPT system. The equivalent circuit of such series-series resonant WPT system can be described in Fig. 2. The use of a series capacitor in both of the transmitter and receiver circuit serves to reduce or cancel the reactance in the power flow path, i.e. $\omega L-1 /(\omega C)=0$, if the operating frequency is set at the resonant frequency of the LC resonant tank. How to use or design the resonant capacitor depends on applications. For relative low frequency, e.g. up to a few MegaHertz, a discrete capacitor components of low capacitance is needed. But for very high frequency operation, e.g. exceeding a few Mega-Hertz, the parasitic capacitance of the transmitter and receiver coil could form the required resonance capacitor. But the equivalent circuits in both cases are identical in theory.

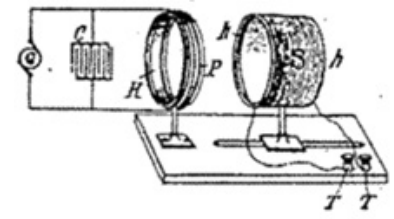

(a)

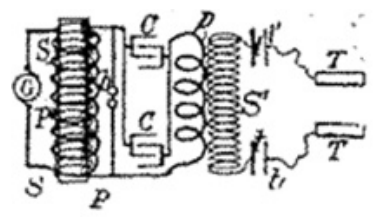

(b)
Fig. 1. One WPT setup based on magnetically coupled series-series resonant circuits tested by Tesla [23].

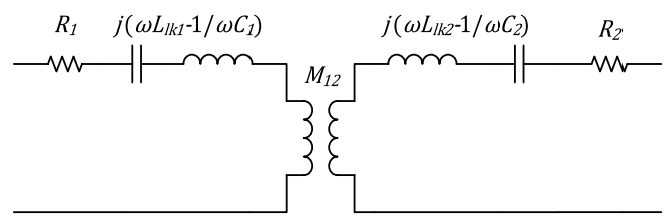

Fig. 2. An equivalent circuit of a magnetically coupled series-series resonant circuit.

\section{B. Use of High Quality Factor and high $k Q$ products in WPT have been well-established concepts}

The concept of Quality factor was popularized by K.S. Johnson in 1914 as the ratio of the reactance to the effective resistance in a coil or a condenser according to an article entitled "The story of $Q$ " published in 1955 [24]. The $Q$ 
factor for an inductor is:

$$
Q=\frac{\omega L}{R}
$$

where $\omega$ is the angular frequency, $L$ is the inductance and $R$ is the winding resistance. It is interesting to note that a very high $Q$ value of 1000 was considered in 1955 [24]. A relative recent investigation into WPT with a $Q$ factor up to 1000 was also considered in a study published in 2006 [25].

Back to Tesla's work reported in 1898 [23], he explained the operation of the system with the emphases on the use of

(i) high frequency,

(ii) winding resistance as low as possible;

(iii) the importance of establishing synchronism between the oscillations in the primary and secondary circuits.

The first two points technically refer to the use of a large $\omega$ and a small $R$ for equation (2). Therefore, the essence of his descriptions on the operating conditions essentially means the requirements for a high $Q$ factor, although $Q$ factor might not a popular technical term in 1898 .

From early 1960s to present, the principles of magnetic resonance and maximization of the $k Q$ product have been central to WPT for medical implants and power electronics applications. In 1961, John Schuder and his team [26] used magnetically coupled resonant circuit for wireless power transfer through the chest wall of an animal to power an artificial heart. The equivalent circuit is shown in Fig. 3. Schuder reported that the power loss was inversely proportional to the product of the mutual coupling coefficient $(k)$ and quality factor $(Q)$ of the receiver coil. Since the power loss is inversely proportional to the energy efficiency $(\eta)$, Schuder's discovery led to the important understanding that:

$$
\eta \propto k Q
$$

By 1970, Schuder managed to use series resonant tanks in both of the transmitter and receiver circuits to transfer over 1 $\mathrm{kW}$ through animal skin based on similar principle [27]. High $Q$ factor was achieved by using litz wire and an operating frequency of $470 \mathrm{k} \mathrm{Hz}$.

The idea of achieving high energy efficiency through maximizing the $k Q$ product has been central to both medical and power electronics research communities for many decades. The transmission distance is inversely proportional to $k$. Thus, the only way to increase WPT energy efficiency for a given distance is to increase $Q$. Tesla's suggestions of using high-frequency operation and winding resistance as low as possible in fact pointed to the same principle. This important principle applies to both short-range and midrange WPT applications.

If the quality factors of the two magnetically coupled windings are not identical, E.S. Hochmair in 1984 shows that the $k Q$ product becomes [28]:

$$
k Q \text { product }=k \sqrt{Q_{1} Q_{2}}
$$

where $Q_{1}$ and $Q_{2}$ are the quality factors of the two windings. The operating frequency was set at $11.7 \mathrm{MHz}$ in [28]. If the two magnetically coupled windings are identical, (5) will converge to (4). A detailed analysis of the energy efficiency of a WPT system with non-identical coupled coils can also be found in [29].

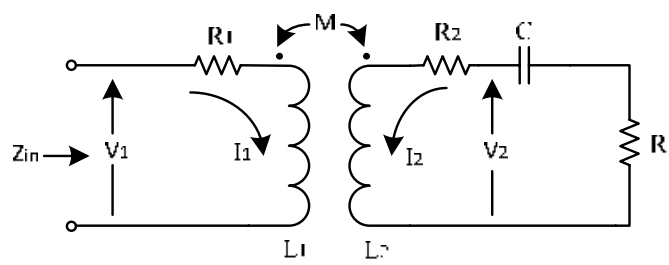

Fig. 3. A magnetically coupled resonant circuit used for WPT in [27].

\section{Examples of Magnetic Resonance application in short- range WPT systems}

While WPT can in principle be classified as magnetic induction and magnetic resonance, it is important to note that most of the WPT activities over the last century involve primarily magnetic resonance. Magnetic induction is used only in a few applications such as wireless charging stands for electric tooth brushes. Magnetic induction based applications typically share the common features of having high coupling coefficient and the receiver coil fixed in position. These applications essentially treat the magnetically coupled transmitter and receiver coils like a pair of transformer windings.

Among WPT works conducted since 1960s, magnetic resonance and high $k Q$ product have been common knowledge central to WPT research and applications in medical implants, mobile robots, inductive pickups, and Qi-compatible consumer electronic products. In particular, WPT research works published by the power electronics community since 1980s are based on magnetic resonance. The exact operating frequency is usually slightly higher than the actual resonance frequency of the resonant tanks. The reason is to utilize the advantage of magnetic resonance and at the same time achieve soft-switching for the power inverter used in the transmitter circuit. A few examples are listed as follows:

- 1990 A. Ghahary and B. Cho [7] used magnetic resonance technique to transfer $48 \mathrm{~W}$ in a loosely coupled transcutaneous energy transmission. The coupling coefficient is 0.1 and the operating frequency is 53 $\mathrm{kHz}$. The system energy efficiency was $72 \%$. The power capability was expanded to $150 \mathrm{~W}$ in 1992 [31].

- 1994 A.W. Green and J. Boys [8] pioneered the inductive power transfer (IPT) systems for the manufacturing industry. Such WPT technique based on magnetic resonance has now become a major industry [31]. The IPT systems are now commonly used in the production lines in clean rooms for the integrated circuit industry. Similar 
ideas are being expanded into R\&D activities for static and dynamic wireless charging of electric vehicles.

-1999 S.Y. Hui and S.C. Tang [32] demonstrated that power and signal could be transferred between two planar printed coils based on magnetic resonance without using magnetic core. Such coreless printedboard transformer became the first embeddable electrical isolation transformer in industrial gatedrive circuits for power electronics switches [33]. It was later used for wireless charging of mobile phone [13]. When turned into a multilayer array structure, this concept led to the first wireless charging pad with free-positioning feature for portable consumer electronic devices [34].

-2000 Y. Jang and M. Jovanovic [12] developed a series-series resonant system to wirelessly charging mobile phones for a wide voltage range. Frequency control technique was used to maintain constant power flow. For $4.5 \mathrm{~W}$, a system energy efficiency exceeding $70 \%$ was achieved.

\section{Use of Magnetic Resonance for mid-range WPT}

The use of magnetic resonance for mid-range WPT application is not new. A 1937 article [35] explains an experimental setup (Fig. 4) installed in the Franklin Institute, Philadelphia where Tesla had given his WPT lecture. The circuit on the left-hand side of Fig. 4 is the transmitter circuit, which consists of a driving loop and a resonator coil (called antenna in [35]). The receiver circuit is on the righthand side. It can be placed with a variable distance from the transmitter circuit. The receiver circuit consists of a receiver resonator coil which is connected to an adjustable condenser so that the idea of tuning the resonance frequency for optimal power transfer can be demonstrated for different distances between the transmitter and receiver resonant coils. The operating frequency was $100 \mathrm{MHz}$. The dimensions of the transmitter and receiver resonator coils are $0.75 \mathrm{~m}$. This setup was used to demonstrate WPT over a distance up to 3 meters for powering a light bulb. So this is a setup suitable to demonstrate the short-range and mid-range WPT.

The idea of using a driving loop to couple with the transmitter resonator coil is an important concept. In fact, the 4-coil system presented in [18] uses one driving loop coupled to the

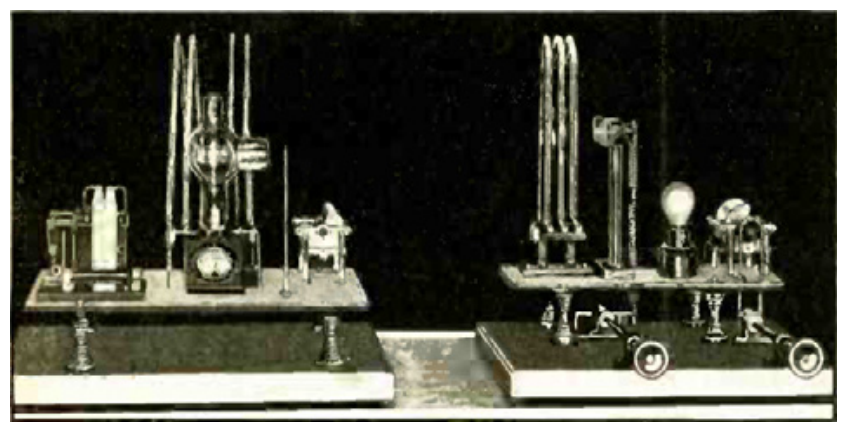

Fig. 4. Mid-range WPT setup in the Franklin Institute, Philadelphia [35] transmitter resonator coil and a load loop coupled to the receiver resonator coil. But the original idea of coupling the resonator coil with a loop actually came from [35].

\section{The Present \& Future Trends}

As mentioned previously, the availabilities of Litz wires and modern power electronics have provided the needed technologies for WPT. The IPT systems have been deployed in manufacturing facilities. Because each manufacturing facility may be different from the others, there is so far no need to form an international standard for IPT systems. However, the situation is quite different for wireless charging of portable consumer electronics. With different mobile phone manufacturers using their own proprietary charging protocols in the 1990s, there was an obvious need from the consumers' point of view that a common charging standard should be adopted. The number of chargers manufactured in 2013 exceeded 2 billion. In an estimation made in 2009 [36], an annual reduction of about 51000 tons of chargers would be achieved if a common charging protocol was adopted. Standard approaches can be adopted in the both wired charging and wireless charging.

The GSM association has made tremendous efforts in this regard for the wired approach. So far, the majority of the mobile phone manufacturers have agreed to use the miniUSB as the standard wired charging protocol. While this is very good news to the environment, consumers should be aware that there are still major mobile phone manufacturers which not only continue to use their own proprietary charging protocols, but they keep on changing them with new models so that consumers have to keep on buying new chargers. Consumers should exert their power to support manufacturers that adopt sustainable policy in their product designs.

\section{A. The Evolving "Qi" Standard by Wireless Power Consortium}

Founded initially with 8 companies in November 2008 [37], the Wireless Power Consortium (WPC) has grown to include over 220 companies worldwide by October 2016. The WPC launched the world's first wireless charging standard "Qi" (pronounced as Chee) in August 2010. So far, this is the most successful wireless charging standard in commercial terms because over 790 "Qi-certified" products have been registered with WPC by October 2016, let alone many other products claimed to be Qi-compatible, Qicompliant or Qi-approved.

The expanding applications and power capabilities of wireless charging are reflected from the evolution of the Qi standard. Based on the information from the WPC website [38], the Qi standard has evolved from version 1.0, 1.1 to 1.2. The main features of these three versions of the standard are tabulated in TABLE I. The current version of the Qi specification has version number 1.2.2. The operating frequency range of Qi is within $105 \mathrm{kHz}$ to $205 \mathrm{kHz}$. This frequency range has been adopted in switched mode power 
supplies for over 3 decades. System energy efficiency above $70 \%$ can generally be achieved at full load. The Qi standard covers primarily short-range WPT applications. The receiver coils of the loads are placed in close proximity of the transmitter coils. The transmission distance is up to about $4 \mathrm{~cm}$. Consequently, the magnetic flux for WPT is essentially enclosed and thus human exposure to electromagnetic radiation is usually not an issue. The recent inclusion of foreign object detection $(\mathrm{FoD})$ is another important step forward in enhancing safety.

TABLE I

Sumary of the Key Features of the Versions of Qi STANDARD [38]

\begin{tabular}{l}
\hline \hline Version 1.0 \\
\hline • Qi transmitter delivers 5 Watt power into a Qi phone. \\
- Choices of transmitter designs include single coil transmitter, coil array \\
transmitter, and moving coil transmitter. \\
• High flexibility in design of Qi receivers. \\
- Limited flexibility in the design of Qi transmitters. \\
\hline Version 1.1 \\
\hline - Increased design freedom for transmitters. One can now choose \\
between 12 different transmitter specifications. \\
- Increased sensitivity of "Foreign Object Detection". This prevents \\
heating of metal objects in the neighborhood of an active transmitter. \\
- The possibility to power a Qi transmitter with a USB charger. \\
\hline Version 1.2 \\
\hline - Fast charging. The possibility for transmitters to deliver up to 15 Watt \\
power and the option for receivers to obtain up to 15 Watt. \\
- An improved thermal test for transmitters. \\
- Improved timing requirements. \\
- Changed limits for Foreign Object Detection. \\
- Optional unique identifier for power receivers (WP-ID). \\
\hline \hline
\end{tabular}

\section{B. Charging Standard by AirFuel Alliance}

After the establishment of the WPC, alternative organizations have been formed with the hope of setting up wireless charging standards to cover other forms of WPT applications. Formed in 2012, the Power Matters Alliance (PMA) and the Alliance for Wireless Power (A4WP) were two examples. In 2015, PMA and A4WP merged together to form the AirFuel Alliance [39]. It should be noted that there are overlaps of memberships between the AirFuel Alliance and the WPC.

Different from the WPC which focuses primarily shortrange applications, the AirFuel Alliance was set up to develop and maintain the standards for a form of wireless power that allowed additional spatial freedom. The aim was to develop a standard that could simultaneously charge a multiple devices, ranging from low-power bluetooth devices to laptop computers and also covering both short-range and mid-range applications. An illustration of this objective is shown in Fig. 5. Some other important features of the technologies being promoted by the AirFuel Alliance are the choices of $6.78 \mathrm{MHz} \pm 15 \mathrm{kHz}$ as the operating frequency for power transfer and $2.4 \mathrm{GHz}$ for control and communication signals. In principle, previous WPT technologies developed over the century can be applied to both relatively low frequency operations such as $105 \mathrm{kHz}-205 \mathrm{kHz}$ for WPC

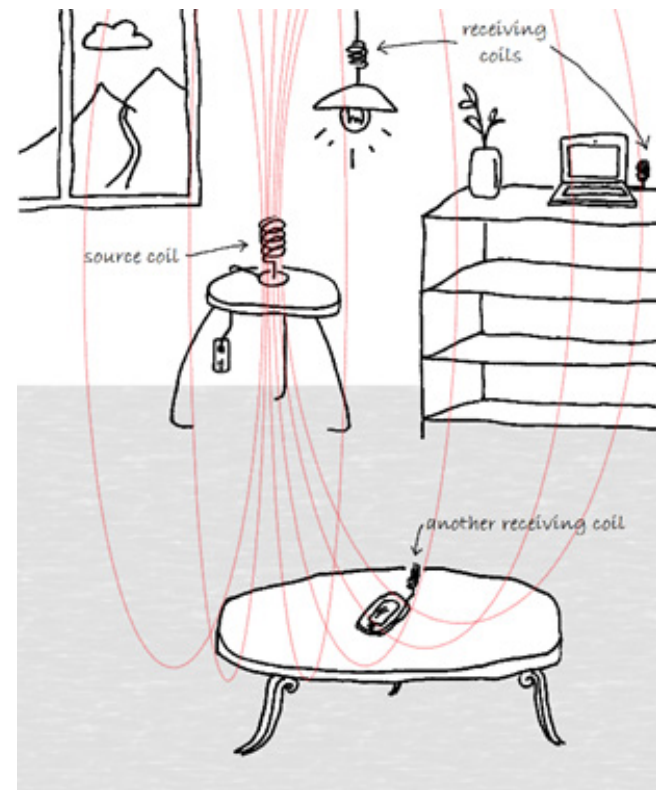

Fig. 5. An illustration of the WPT concept with spatial freedom.

or $6.78 \mathrm{MHz} \pm 15 \mathrm{kHz}$ for AirFuel Alliance.

\section{New Health Concern on Human Exposure to Magnetic Field at $7 \mathrm{MHz}$}

Compared with WPC which focuses primarily on shortrange WPT applications, AirFuel Alliance chooses a much higher WPT frequency which enables higher compactness of the power and magnetic circuits and a high $Q$ factor. As explained previously, increasing the value of $Q$ allows the mutual coupling to decrease for a given $k Q$ product. A small value of $k$ implies a relatively long transmission distance for WPT, making it possible to increase spatial freedom. However, the idea of increasing spatial freedom (Fig. 5) also implies the requirements of human exposure to ac magnetic field.

The main concern of using $6.78 \mathrm{MHz}$ lies not only in the technical performance of the WPT technologies available today, but in the potential health hazards raised recently by quantum biologists about the adverse effects of ac magnetic field at $7 \mathrm{MHz}$ on cell growth. In 2014, new practical evidence was presented in [40] to show that even a weak magnetic field of $10 \mu \mathrm{T}$ at $7 \mathrm{MHz}$ could enhance cell proliferation. Note that an ac magnetic field of $10 \mu \mathrm{T}$ is considered to be weak because the static magnetic field of the earth is about $45 \mu \mathrm{T}$. It is suggested in [40] that magnetic field at $7 \mathrm{MHz}$ could influence the electronic spins of cells to form radicals. The authors of [40] criticize the existing safety regulations which only consider the thermal stress on cells based on the specific absorption rate (Watt per kilogram of tissue) as inadequate. They concluded that "In contrast to the spin-pair mechanism, specific absorbed radiation (SAR) measurements of macroscopic tissue heating represent a naïve approach to bio-magnetic RF- interactions because it ignores nanoscale physics and spin chemistry, which can potentially have profound biological effects." Following 
up the work in [40], the authors of [41] provide possible explanations for observed changes in growth rates of cancer cells and radical concentration upon exposures to magnetic fields below the ICES and ICNIRP reference levels.

It is therefore important for international regulatory bodies to re-examine existing health and safety regulations in view of the new evidence because $7 \mathrm{MHz}$ is close to the Industrial, Scientific and Medical (ISM) radio band of 6.78 $\mathrm{MHz}$ (which happens to be the operating frequency selected by the AirFuel Alliance). The author believes that using 6.78 $\mathrm{MHz}$ for short-range applications in which the magnetic flux is enclosed or shielded (like the application framework in the WPC) should not encounter the same potential health issue. The choice of operating frequencies does not affect the validity of many existing WPT technologies in terms of the technical viabilities. Stakeholders in the WPT industry should consider a common standard that addresses both technical performance and health and safety concerns of consumers.

\section{SAE TIR J2954 Guidelines for Wireless Charging of Plug-In Electric Vehicles}

SAE International, initially established as the Society of Automotive Engineers, is a professional association and standards developing organization for engineering professionals in various industries. In May 2016, SAE launched SAE TIR J2954 as an industry-wide specification guideline that defines acceptable criteria for interoperability, electromagnetic compatibility, minimum performance, safety and testing for wireless charging of light duty electric and plug-in electric vehicles [42]. The current version addresses unidirectional charging from grid to vehicle. Bidirectional energy transfer is not covered. This guideline calls for a common operating frequency of $85 \mathrm{kHz}$, which is easily manageable with existing power electronics technology even at $10 \mathrm{~kW}$. It proposes four classes of wireless power transfer: $3.7 \mathrm{~kW}, 7.7 \mathrm{~kW}, 11.0 \mathrm{~kW}$, and $22.0 \mathrm{~kW}$. It is intended to be used for stationary applications. Dynamic wireless charging will most likely be considered in future guidelines when dynamic wireless charging technology becomes more mature.

\section{E. From Directional to Omni-directional WPT}

Existing commercial WPT products are based on directional wireless power flow. One new development of directional WPT is the use of the wireless domino WPT system for powering online monitoring system in power transmission networks. Energy can be harvested from the magnetic field of a high-voltage power cable and transferred to the high-voltage transmission tower to power the online monitoring system (Fig. 6). Coil-resonators can be embedded inside the insulation discs as shown in Fig. 7. The new insulation string structure provides both high-voltage insulation and WPT capabilities [43], [44].

Research into omnidirectional WPT has been reported in [25]. Fig. 8 shows one example of an omnidirectional

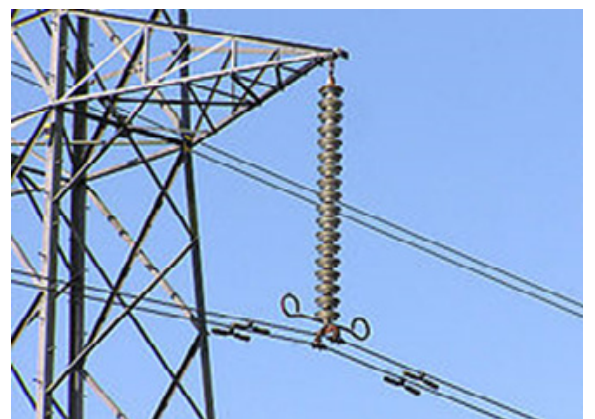

Fig. 6. Use of patent-pending insulation string with embedded coilresonators for WPT [43], [44].

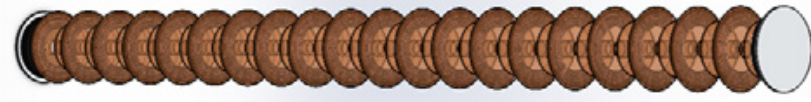

Fig. 7. Novel insulation string" with (i) High-Voltage insulation \& (ii) Wireless Power Transfer capabilities [43], [44].

WPT container in which the receiver coil of the load can obtain wireless power regardless of its orientation inside the container. The omnidirectional WPT system in Fig. 8 consists of three orthogonal transmitter coils excited by a patent-pending non-identical current control method. The control principle of this omnidirectional WPT system has been developed [45]. This system can be used for simultaneous charging of a range of portable electronics products, regardless of the orientations

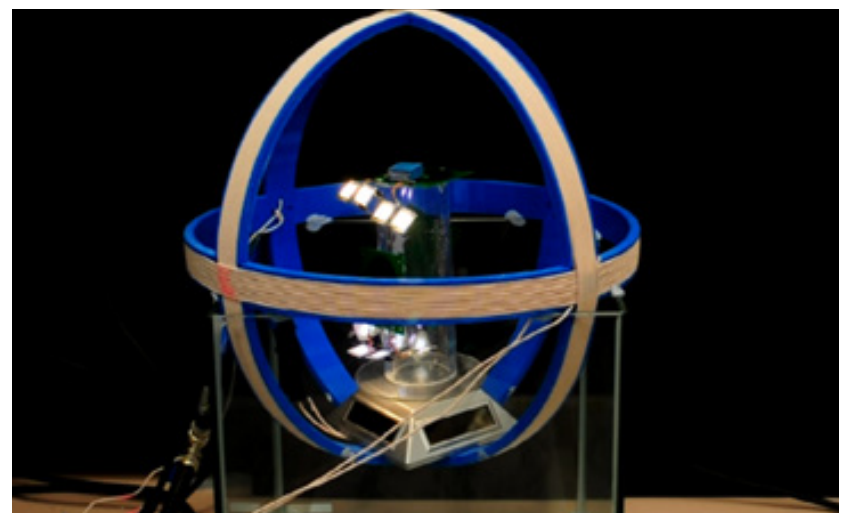

Fig. 8. An omnidirectional WPT system based on three orthogonal transmitter coils and non-identical current-control [45] (Courtesy of the University of Hong Kong).

of the receiver coils. It is suitable for charging a variety of electronics devices (such as smart phones and smart watches) in a highly user-friendly and convenient manner.

\section{Avoidance of Some Pitfalls In WPT}

Besides understanding the historical developments of WPT, researchers entering this exciting field should equip themselves with some basic understanding so as to avoid certain pitfalls. These issues include the use of the appropriate terminologies, the scientific principles and choices of technologies. 


\section{A. Understanding the Correct Terminologies}

Power electronics (PE) researchers/engineers are usually interested in "power" transfer, while Radio-Frequency (RF) researchers focus on "signal" transfer. They could use similar terms which could have totally different technical meanings. This issue was raised and explained in a critical review [46]. For a RF researcher, the term "impedance matching" often means matching the load impedance with the source impedance. On the contrary, a PE researcher often uses the same term to refer to designing a resonant capacitor so that its negative reactance can cancel the positive reactance in the power flow path. Another example is the term "efficiency". A RF researcher often considers the "power leaving the output terminals" of an ac power source as the "input power" of a RF system. A PE researcher considers the "power entering the input terminals" of an ac power source as the "input power". It is a common practice for a PE researcher to consider the power loss in the power source in the calculation of the overall system energy efficiency.

\section{B. Understanding the Correct Operating Principles}

As originally pointed out in [46], WPT operations can be classified as under either the Maximum Energy Efficiency (MEE) Principle or the Maximum Power Transfer (MPT) Principle. PE researchers are familiar with the operations of switched mode power supplies that should have minimum source resistance and switching loss. They tend to adopt the MEE principle because overall system energy efficiency is often a top priority in power transfer. Their designs usually include the considerations of the source resistance that should be as small as possible.

RF researchers tend to consider signal transfer with the equivalent load impedance matching the source impedance in order to meet the maximum power transfer theorem. However such approach, when used for power transfer, suffers an inherent problem that the overall energy efficiency will never be higher than $50 \%$. Even in the ideal case that the source resistance is equal to the load resistance, half of the input power will be dissipated in the source resistance. For WPT applications in which energy efficiency is of top priority, the MEE principle is the preferred option instead of the MPT principle. Therefore, ignoring the source resistance in WPT system design will lead to very low energy efficiency. While the transmission efficiency (without considering the power loss in the power source) in [18] is about $40 \%$, the overall system efficiency including the power loss in the power source is only $15 \%$. So the work in [18] illustrates the problems of ignoring the source resistance and of using the MPT principle in WPT applications of significant power. As different applications require different strategies of designs and operating principles, some general guidelines for choosing the appropriate operating methods have been addressed in [22] and now expanded in TABLE II.

TABLE II

General Guidelines of Choosing the Operating Principles

\begin{tabular}{|c|c|c|}
\hline & MEE & MPT \\
\hline Impedance matching & $\begin{array}{c}\text { To design the resonance capacitor to compensate } \\
\text { the leakage inductance }\end{array}$ & $\begin{array}{l}\text { To match the input impedance of the WPT } \\
\text { system with the source impedance }\end{array}$ \\
\hline System efficiency & Can be higher than $50 \%$ & $\leqslant 50 \%$ \\
\hline Source resistance & As low as possible $(\mathrm{RS} \rightarrow 0$ ) & Dependent on the power source \\
\hline Suitable power level if efficiency is a priority & $\geqslant 1 \mathrm{~W}$ & $<1 \mathrm{~W}$ \\
\hline Applications & Energy efficiency is a priority & Energy efficiency is not a priority \\
\hline Feature of a 2-coil system & $\begin{array}{l}\text { High efficiency for short-range, but very low } \\
\text { efficiency for mid-range applications }\end{array}$ & $\begin{array}{l}\text { Low efficiency for both short- and mid-range } \\
\text { applications }\end{array}$ \\
\hline $\begin{array}{l}\text { Feature of a } 3 \text {-coil system (including an } \\
\text { intermediate relay resonator) [47] }\end{array}$ & $\begin{array}{l}\text { Under some conditions, a 3-coil system can be } \\
\text { more efficient than a 2-coil one. }\end{array}$ & \\
\hline $\begin{array}{l}\text { Feature of a 4-coil system based on two } \\
\text { resonators and two coupled coils [18] }\end{array}$ & & $\begin{array}{c}\text { Maximized transmission distance at the expense } \\
\text { of energy efficiency. }\end{array}$ \\
\hline $\begin{array}{l}\text { Feature of multi-coil system based on relay } \\
\text { resonators }[43],[44]\end{array}$ & $\begin{array}{c}\text { A good compromise between energy efficiency } \\
\text { and transmission distance if relay resonators are } \\
\text { allowed. }\end{array}$ & \\
\hline
\end{tabular}

\section{Conclusions}

Despite the original concept was developed over a century ago, WPT is still a fast growing R\&D area with immense application potentials. With the understanding of the historical WPT developments, it is hoped that visionary researchers would take WPT to new heights in the future. International cooperation plays an instrumental role in setting up wireless charging standards to serve the industrial community and users of wireless power. It is natural that these standards will evolve with time and progress of WPT technology. Wireless power not only provides a wide range of functions for various industrial and domestic applications, it also offers sustainable solutions to reduce tonnes of unnecessary chargers and their associated electronic waste. This point is particularly important to the industry of portable consumer electronics devices. With new evidence 
of health concerns presented by quantum biologists about the use of magnetic field at $7 \mathrm{MHz}$, more research efforts should be devoted to study the effects of magnetic field on cell growth. International health and safety organization should re-examine the coverage of existing standards. So far, WPT has reached commercialization stage in consumer electronics and manufacturing industry. It is envisaged that the next sectors that would benefit from WPT include electric vehicles and medical implants. WPT is no longer a discipline for electrical engineers and scientists only. It has evolved into a multidisciplinary subject involving quantum biologist, biological and biomedical scientists.

\section{REFERENCES}

[1] Nikola Tesla, "High frequency oscillators for electro-therapeutic and other purposes", The Electrical Engineer. vol. XXVI, no. 550, Nov. $17,1898$.

[2] Nikola Tesla, "Transmission of electrical energy without wire", Electrical World and Engineer, Mar. 5, 1904 [online] www.tfcbooks. com/tesla/.

[3] M. Hutin and M. Leblanc, "Transformer system for electric railways", US patent 527 857, Oct. 23, 1894.

[4] "Nikola Tesla 1857 - 1943", Proceedings of the I.R.E., May 1943, pp. 194.

[5] R. Lomas, "The Man Who Invented the Twentieth Century - Nikola Tesla - Forgotten Genius of Electricity”, U.K., Headline Book Publishing, 1999

[6] G. B. Joung and B. H. Cho, "An energy transmission system for an artificial heart using leakage inductance compensation of transcutaneous transformer", IEEE Transactions on Power Electronics, vol.13, no.6, pp. 1013-1022, 1998.

[7] A. Ghahary and B.H. Cho, "Design of a transcutaneous energy transmission systems using a series resonant converter", IEEE Power Electronics Specialists Conference, 1990, pp.1-8.

[8] A.W. Green and J.T. Boys, "10k Hz inductively coupled power transfer - concept and control", 1994 Power Electronics and Variable Speed Drives Conference, 1994, pp. 694-69.

[9] G.A.J. Elliott, J.T. Boys and A.W Green, "Magnetically coupled systems for power transfer to electric vehicles", Proceedings of 1995 International Conference on Power Electronics and Drive Systems, 1995, vol. 2, pp. 797 - 801.

[10] Y. Jang and M. Jovanovic, "A contactless electrical energy transmission system for portable-telephone battery chargers", IEEE Transactions on Industrial Electronics, vol. 50, no. 3, pp. 520 - 527, Jun. 2003.

[11] C.-G. Kim, D.-H. Seo, J.-S. You, J.-H. Park and B. H. Cho, "Design of a contactless battery charger for cellular phone", IEEE Transactions on Industrial Electronics, vol. 48, no. 6, pp. 12381247, Dec. 2001.

[12] Yungtaek Jang, M.M. Jovanovic, "A contactless electrical energy transmission system for portable-telephone battery chargers", Twenty-second International Telecommunications Energy Conference, 2000. INTELEC., pp. 726 - 73.

[13] B. Choi, J. Nho, H. Cha, T. Ahn, and S. Choi, "Design and implementation of low-profile contactless battery charger using planar printed circuit board windings as energy transfer device", IEEE Transactions on Industrial Electronics, vol. 51, no. 1, pp. 140147, Feb. 2004.

[14] S.Y.R. Hui, "Planar inductive battery charger", UK Patent GB2389720B, Sept. 7, 2005.

[15] L. Cheng, J.W. Hay and P. Beart, "Contact-less power transfer”, US Patent 6,906,495, Jun. 14, 2005

[16] S.Y.R. Hui, "Planar Wireless Charging Technology for Portable Electronic Products and Qi", Proceedings of the IEEE [Invited Paper] vol. 101 , no. 6, pp. 1290-1301, 2013.
[17] G. Covic and J.T. Boys, "Inductive Power Transfer", Proceedings of the IEEE [Invited Paper], vol. 101, no. 6, pp. 1276-1289, 2013.

[18] A. Kurs, A. Karalis, R. Moffatt, J. D. Joannopoulos, P. Fisher and Marin Soljac 'ic', "Wireless Power Transfer via Strongly Coupled Magnetic Resonances", Science, vol. 317, pp. 83-86, Jul. 2007.

[19] S. Cheon, Y.H. Kim, S.Y. Kang, M. L. Lee, J.M. Lee, and T. Zyung, "Circuit-model-based analysis of a wireless energy-transfer system via coupled magnetic resonances", IEEE Trans. Industrial Electronics, vol. 58, no. 7, pp. 2906-2914, Jul. 2011.

[20] C.J. Chen, T.H. Chu, C.L. Lin, and Z.C. Jou, "A study of loosely coupled coils for wireless power transfer", IEEE Trans. Circuits and Systems - II: Express Briefs, vol. 57, no. 7, pp. 536-540, Jul. 2010.

[21] M. Kiani, and M.. Ghovanloo, "The circuit theory behind coupledmode magnetic resonance-based wireless power transmission," IEEE Trans. Circuits Systems - I, vol. 59, no. 8, pp. 1-10, Aug. 2012.

[22] S.Y.R. Hui, "Magnetic resonance for wireless power transfer [A Look Back]", IEEE Power Electronics Magazine, vol. 3, no. 1, pp. 14-31, 2016.

[23] Nikola Tesla, "On light and other high frequency phenomena", Lecture Delivered before the Franklin Institute, Philadelphia, February 1893, and before the National Electric Light Association, St. Louis, March 1893. [online] www.tfcbooks.com/tesla/.

[24] Estill I. Green, "The story of Q", Bell Telephone System - Technical Publication Monograph 2491, pp. 1-11 (also published in American Scientist, vol. 43, pp. 584-594, Oct. 1955).

[25] K. O'Brien, "Inductively coupled radio frequency power transmission system for wireless systems and devices", Ph.D thesis, Chapter 5, University of Technoloogy, Dresden, Germany, 2006.

[26] J.C. Schuder, H.E. Stephenson and J.F. Townsend, "High level electromagnetic energy transfer through a closed chestwall, IRE Int. Conv. Rec., vol. 9, pp. 119-126, 1961.

[27] J.C. Schuder, J.H. Gold and H.E. Stephenson, "An inductively coupled RF system for the transmission of $1 \mathrm{~kW}$ of power through the skin", IEEE Transactions on Biomedical Engineering, vol. 18, no. 4, pp. 265-273, Jul. 1971.

[28] E. S. Hochmair "System Optimization for Improved Accuracy in Transcutaneous Signal and Power Transmission", IEEE Trans. Biomed. Eng., vol. BME-31, pp. 177-186, Feb. 1984.

[29] C. M. Zierhofer and E. S . Hochmair, "Coil Design For Improved Power Transfer Efficiency In Inductive Links", 18th Annual International Conference of the IEEE Engineering in Medicine and Biology Society, Amsterdam, pp.1538-1539, 1996.

[30] A. Ghahary and B. Cho, "Design of a transcutaneous energy transmission system using a series resonant converter", IEEE Transactions on Power Electronics, vol. 7, no. 2, pp. 261-269, 1992.

[31] J.T. Boys and G. Covic, "The Inductive Power Transfer Story at the University Of Auckland", IEEE Circuits \& Systems Magazine, vol. 15 , no. 2, pp. 6 - 27, 2015.

[32] S.Y.R. Hui and S.C. Tang, "Coreless Printed-Circuit-Board (PCB) Transformers And Operating Techniques Therefor", Patent EP(GB)0935263B, filed 1999, granted May 2004.

[33] M. Munzer, W. Ademmer, B. Strzalkowski, and K. T. Kaschani, "Insulated signal transfer in a half bridge driver IC based on coreless transformer technology," in Proc. 5th Int. Conf. Power Electron. Drive Syst., 2003, vol. 1, pp. 93-96.

[34] S.Y.R. Hui and W.C. Ho, "A new generation of universal contactless battery charging platform for portable Consumer Electronic equipment", IEEE Transactions on Power Electronics, vol. 20, no. 3, pp. 620 - 627, May 2005.

[35] Hugo Gernsback (Editor), "Lighting lamp by S-W- Radio", Short Wave \& Television, pp. 166 and 191, Aug. 1937.

[36] D. Lowther and R. Fogg, "Mobile industry unites to drive universal charging solution for mobile phones," GSM Association Press Release. [Online]. Available: http://www.gsmworld.com/newsroom/ press-releases/2009/2548.htm.

[37] Menno Treffers, "History, Current Status and Future of the Wireless Power Consortium and the Qi interface specification", IEEE Circuits \& Systems Magazine, vol.15, no. 2, pp. 28-31, May 2015.

[38] Wireless Power Consortium website: https://www.wirelesspowerconsortium.com/.

[39] AirFuel Alliance website: http://www.airfuel.org/. 
[40] R.J. Usselman, I. Hill, D.J. Singel and C. F. Martino, "Spin Biochemistry Modulates Reactive Oxygen Species (ROS) Production by Radio Frequency Magnetic Fields", PLOS, vol. 9, no. 3, pp. 1-2, Mar. 2014

[41] Frank Barnes and Ben Greenbaum, "Magnetic Field Effects on Biology and Potential Health Effects Below the ICES and ICNIRP Reference Levels", IEEE Wireless Power Transfer conference, Boulder, N.C., USA, May 2015, Paper T5.8, pp. 1-4.

[42] http://standards.sae.org/wip/j2954/ http://standards.sae.org/wip/ j2954/.

[43] S.Y.R. Hui and C. Zhang, "A wireless power transfer system", U.S. Provisional Patent Application Serial No. 62/256,726, filed on Nov. $18,2015$.

[44] C. Zhang, N. Tang, W.X. Zhong, C.K. Lee and S.Y.R. Hui, “A New Energy Harvesting and Wireless Power Transfer System for Smart Grid", IEEE 7th International Symposium on Power Electronics for Distributed Generation Systems (PEDG), Vancouver, Canada, Jun. 2016, pp. 1-5.

[45] C. Zhang, Deyan Lin and S.Y.R. Hui, "Basic Control Principles of Omnidirectional Wireless Power Transfer", IEEE Transactions on Power Electronics, vol. 31, no. 7, pp. 5215-5227, Jul. 2016.

[46] S.Y.R. Hui, W.X. Zhong and C.K. Lee, "A critical review on recent progress of mid-range wireless power transfer", IEEE Transactions on Power Electronics, vol. 29, pp. 4500-4511, Sept. 2014.

[47] W.X. Zhong, C. Zhang, X. Liu and S.Y.R. Hui, "A Methodology for Making a 3-Coil Wireless Power Transfer System More Energy Efficient Than a 2-Coil Counterpart for Extended Transmission Dis- tance", IEEE Transactions on Power Electronics, vol. 30, no. 2, pp. 933-942, 2015.

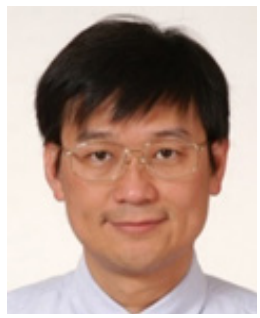

S. Y. (Ron) Hui received his BSc (Eng) Hons at the University of Birmingham in 1984 and a D.I.C. and $\mathrm{PhD}$ at Imperial College London in 1987. Presently, he holds the Philip Wong Wilson Wong Chair Professorship at the University of Hong Kong and a part-time Chair Professorship at Imperial College London.

He has published over 300 technical papers, including more than 220 refereed journal publications. Over 60 of his patents have been adopted by industry. He is an Associate Editor of the IEEE Transactions on Power Electronics and IEEE Transactions on Industrial Electronics, and an Editor of the IEEE Journal of Emerging and Selected Topics in Power Electronics. His inventions on wireless charging platform technology underpin key dimensions of Qi, the world's first wireless power standard, with freedom of positioning and localized charging features for wireless charging of consumer electronics. He received the IEEE Rudolf Chope R\&D Award from the IEEE Industrial Electronics Society and the IET Achievement Medal (The Crompton Medal) in 2010, and IEEE William E. Newell Power Electronics Award in 2015. He is a Fellow of the Australian Academy of Technological Sciences \& Engineering and also the Royal Academy of Engineering, U.K. 